\section{Patient choice and narrative ethics}

\author{
John Launer
}

Most doctors subscribe to the idea of offering patients a choice about their medical management: for example, choosing whether to start preventive treatment for a risk factor like hypertension, or deciding which hospital to go to for an operation. Of course, such choices may not be as straightforward as they seem. Doctors may give a steer by what they mention in terms of risks and benefits, and some patients prefer their doctors to make decisions for them anyway. In spite of this, engaging in dialogue about choice has become one of the hallmarks of good medical practice. The right to choose has become a central feature of medical consumerism. There are also whole areas of medical discourse and training - like patient-centred medicine ${ }^{1}$ and shared decision-making ${ }^{2}$ - that focus on the idea.

As well as being able to help patients make decisions, doctors also need to offer choices of a different kind during the consultation: inviting people to choose what they want to talk about at any moment. Although the skills for doing this receive far less attention than those concerned with decision making, they may be even more important. Consider, for example, these two alternative versions of the same consultation ${ }^{3}$ :

Version A:

Patient: I've come about the spots on my face.

Doctor A: How long have they been there?

Patient: I've had them since I was a teenager. But they've really broken out badly in the last few months.

Doctor A: Have you tried anything for them?

Patient: I've bought a few things at the pharmacist but nothing seems to work.

Doctor A: Well, let's have a look then ...

Version B:

Patient: I've come about the spots on my face.

Doctor B: How long have they been there?

Correspondence to: Dr John Launer, Faculty Development, Health Education England, Stewart House, 32 Russell Square, London WC1B 5DN, UK: john.launer@londondeanery.nhs.uk

\section{POSSIBLE CONVERSATIONS}

Patient: I've had them since I was a teenager. But they've really broken out badly in the last few months.

Doctor B: Do you have any idea why?

Patient: I'm not sure. Could it be stress? Doctor B: Why do you ask?

Patient: Well I lost my job about six months ago, and then my boyfriend left me in the summer and I've been pretty low generally and .... (starts to cry).

Although the opening of the consultation is the same in both versions, the two doctors take it in entirely different directions. Doctor A fails to hear the patient explain that the spots have broken out badly 'in the last few months', or at least decides not to follow this cue. Doctor B not only hears the phrase, but offers the patient a chance to expand on why this may have happened. By the end of the consultation, the patient may still reach the same 'choice'- in the technical sense of which medication she uses for her spots. However, Doctor B's curiosity opens up an additional set of possibilities for her. This includes the option of forgetting about the spots, and exploring a better way of addressing her recent life events. There will then be no prescription. What is commonly meant by 'patient choice' will have turned out to be quite irrelevant.

Moments like this occur very commonly in medical consultations. It is useful to think of them as potential junctions, or 'bifurcations' in the conversation. Typically, as in the example above, such bifurcations offer a chance to explore the personal and emotional aspects of a problem, rather than simply the bodily ones. However, they may also point towards subtle physical symptoms, and hence provide the opportunity to reach a more accurate diagnosis or better treatment. If you look at recordings of doctor-patient interactions, you will become aware of the sheer number of possible conversations that might happen if the doctor were to follow different cues, or give different responses. You might even be struck by the impossibility of any human being able to notice every bifurcation, or to give the best response in every case. Sometimes these moments seem so frequent, and so rich in possibility, that it might be better to describe them as 'multifurcations' - using the biological term for the way that multiple branches spring from a single evolutionary source. Suddenly, it may seem as if the doctors only ever take limited and pre-determined routes across vastly complicated landscapes, or elect to inhabit a sole universe among the infinite number of alternative ones on offer.

Although unnerving, such a realisation offers a radically different view of the consultation, and one that is supported by the field of thought knows as narrative ethics. ${ }^{4}$ According to this view, every juncture in a medical history is seen as a potential opening for offering a choice, so that patients genuinely create their own stories and are no longer controlled by the doctor. This can happen when the doctor notices a cue and tests its potential for narrative development with a question, just as Doctor $\mathrm{B}$ does in the example. It can also involve inviting the patient explicitly to choose which path to take. (eg 'Which aspect of the problem would you like to explore at this point?') As a result, the consultation becomes constructed jointly by both doctor and patient, as each of them respond to the other's immediate verbal feedback and body language. Instead of posing as 'Dr Fixit', the doctor becomes a conversational partner.

Seeing patient choice in terms of conversation-making rather than decisionmaking has many advantages. Patients can direct doctors towards what matters, and articulate what they actually want from the encounter. They can do so far more effectively than if the doctor tries to second guess these things for most of the consultation. The decision about treatment, if needed, arrives though evolution, rather than being mechanically introduced at the end by the doctor, or offered as a token gesture towards patient empowerment. 'Patient choice' is not just about decisions. It can be embedded in every moment of interaction between patient and doctor.

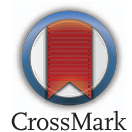

To cite Launer J. Postgrad Med J 2014;90:484.

Postgrad Med I 2014;90:484.

doi:10.1136/postgradmedj-2014-132866

\section{REFERENCES}

1 Stewart M, Brown JB, Weston WW, et al. Patient-Centred Medicine: Transforming the Clinical Method (Second edition). Abingdon, Radcliffe, 2003

2 Edwards A, Elwyn G. Shared Decision-Making in Health Care: Achieving Evidence-Based Patient Choice (Second Edition). Oxford, Oxford University Press, 2009.

3 Launer J, Taking a narrative stance in the consultation. Primary Care Mental Health 2003; 1: 111-12

4 Charon R, Montello M, eds. Stories Matter: The Role of Narrative in Medical Ethics. Abingdon, Routledge, 2002. 